\title{
OVARIAN METASTATIC TUMORS - A LITERATURE REVIEW
}

\author{
N. Bacalbasa ${ }^{1}$, A. Traistaru' ${ }^{2}$, I. Balescu ${ }^{3}$ \\ ${ }^{\prime}$,Carol Davila“ University of Medicine and Pharmacy, Bucharest \\ ${ }^{2}$ Elias University Emergency Hospital, Bucharest \\ ${ }^{3}$, ,Ponderas “ Hospital, Bucharest
}

\begin{abstract}
Ovarian metastatic tumors represents up to $10 \%$ of all ovarian malignancies. The most encountered tumors which may give birth to ovarian cancer are those originating from the gastric tube; however, other malignancies such as breast, cervix, lung or even skin may be associated with ovarian metastatic tumors. This is a literature review of the most frequently seen ovarian metastatic tumors.
\end{abstract}

Keywords: ovarian metastatic tumors, Krukenberg, breast cancer, cervical cancer

\section{INTRODUCTION}

The prevalence of metastatic ovarian tumors ranges between $7 \%$ and $10 \%$ of the ovarian malignant tumors, almost $70 \%$ of them being bilateral. The primary tumor in these cases is most frequently located in the stomach, colon, rectum, appendix, breast, cervix, lung and skin. The high percentage of bilateral ovarian metastases suggests that cancer cells may have a certain affinity for ovarian tissue through a mechanism that is still unclear. The Krukenberg tumor is a type of ovarian metastasis. Diagnostic criteria include the presence of ,signet ring"-like neoplastic cells, mucin secretion and stromal diffuse proliferation that suggest the existence of an interaction between stromal cells and tumor cells. (1)

In a study published in 2008, Kuwabara et al. tried to unravel the mechanisms of ovarian metastasis, elaborating an in vivo model for the development of these tumors in immunosuppressed mice by implanting human neoplastic cells intravenously and intraperitoneally. The results showed that a transmembranare glycoprotein molecule located in the epithelial cells - cadherin E - is involved in the mechanism of formation of the metastasis. After histological examination, in about half of the cases, there was a decreased expression of $E$ cadherin at cellular levels. (1)

\section{OVARIAN METASTASES OF GASTRIC CARCINOMA}

Most ovarian metastases originating from gastric adenocarcinomas are classified morphologically as Krukenberg tumors - bilateral ovarian tumor ordense fibrous stroma surrounded by ,,signet ring" cells. $(2,3)$

In a broader sense, Krukenberg tumors are metastatic ovarian tumors, with the primary tumor being located in the digestive tract, most commonly in the stomach ( $76 \%$ of cases). They are bilateral in $80 \%$ of cases. In 1896, Friedrich Krukenberg described 5 cases of ovarian tumors, in young women with ascites, ovarian surface irregularities and lymphatic invasion. $(4,5)$

Histologically, Krukenberg tumors show diffuse stromal proliferation, they produce mucus and the cells have the appearance of ,signet ring“. In a study by McGill et al on 233 women with gastric neoplasia, he discovered an incidence of $18.2 \%$ of Krukenberg tumor in premenopausal women be-

Corresponding author:

Nicolae Bacalbasa, 2 Dimitrie Racoviță St, Bucharest, Romania

E-mail: nicolae_bacalbasa@yahoo.ro 
tween 40 and 50 years, and $0 \%$ incidence in women at menopause $(6,7)$. Most commonly, the diagnosis is made after a CT scan or pelvic ultrasound examination. Krukenberg tumor represents advanced neoplastic disease, and the average patient survival after diagnosis is 7-14 months. (6-8)

The primary tumor in the stomach may be small, it can affect the gastric wall in a diffuse pattern, giving the appearance of plastic linitis or may not be evident from the beginning to endoscopy and become clinically evident later. On macroscopic examination, the ovaries may be only slightly increased in volume and may suggest the diagnosis of fibroid tumor, due to stromal development. The microscopic examination reveals the presence of „signet ring" cells that are characteristic of adenocarcinomas, and mucinous tubular areas. (2)

A study of 34 patients with gastric cancer and Krukenberg tumor who underwent resection of ovarian metastases after surgical cure of gastric cancer showed a higher median time of survival in patients with complete ovarian metastases resection (11 months) compared to patients with extrapelvic disease ( 9 months). (9)

\section{OVARIAN METASTASES OF COLORECTAL CARCINOMA}

One of the most common tumors affecting the ovary is represented by the metastatic colorectal adenocarcinoma. The patient who presents to the physician can have positive history for colorectal neoplasia, but in some cases the patient can have an ovarian tumor without other complaints or other known malignancies. Ovarian metastases from colorectal adenocarcinoma can mimic mucinous or endometrioid ovarian cancer. The items that suggest the presence of a metastatic tumor, and not a primary ovarian neoplasm, are: the presence of bilateral tumors, nodular surface of the ovaries, tumoral lesions located on the surface of the ovary, extended lymphovascular invasion. $(2,10)$ Luteinized stromal cells is a common finding in ovarian metastases of colorectal adenocarcinomas. Macroscopically, this type of tumor may appear as a cyst or as a solid structure. Other characteristics of the tumor that appear more frequently in ovarian metastases from colorectal cancers are: the presence of segmental necrosis, cell arrangement in cordlike structures and the presence of pleomorphic cells with hyperchromatic nuclei. The presence of adenofibromatous component, benign squamous lesions and coexisting endometriosis, are in favor of a primary ovarian endometrioid carcinoma. Immunohistochemistry may be useful in differentiating metastases from primary tumors $(2,11-14)$ CK 7 while CA125 markers are positive in primary endometrioid ovarian carcinoma and negative in metastases and CK2 and CEA markers are absent in primary tumors and present in metastasis.

\section{OVARIAN METASTASES ORIGINATING FROM PRIMARY TUMORS LOCATED IN THE APPENDIX}

Adenoma and adenocarcinoma of the appendix can determine ovarian mucinous metastatic tumors (borderline or malignant tumors) associated sometimes with pseudomyxoma peritonei (15-19). Histologically, pseudomyxoma peritonei can have two forms: disseminated peritoneal adenomucinosis (DPAM) - mucinous material contains adenomatous epithelial cells, and peritoneal mucinous carcinomatosis (PMCA) - ,signet ring“-like cells and abundant extracellular mucin. In cases of pseudomyxoma peritonei, appendix should be removed even if the macroscopic appearance is normal because at this level there is definitely a small adenoma or adenocarcinoma to be found at histopathological examination. Sometimes the appendix may be very difficult to identify because it is embedded in a mucinous or fibrous tissue mass. Ovarian metastases appear most frequently as unilateral or bilateral cystic tumors. The histopathological report shows mucinous borderline tumor of intestinal type. Nodular appearance of the affected ovary and surface implants advocates for a metastatic tumor. In the case of appendicular cystadenoma, secondary ovarian tumors should be regarded rather as secondary areas of implantation and not the result of appendiceal metastasis. If the appendicular tumor is an adenocarcinoma, ovarian metastases are present with ,signet ring“-like cells, glandular formations, with areas of necrosis, stromal invasion and lymphovascular invasion. Appendiceal goblet cell carcinoid tumors can also metastasize to the ovary, and should be differentiated from metastatic ovarian adenocarcinoma with ,signet ring“-like cells and from the primary ovarian carcinoid (a very rare tumor). (20) The coexistence of an ovarian teratoma represents an important proof of the existence of a primary ovarian carcinoid, but it is necessary to perform immunohistochemical markers to confirm goblet cell carcinoid. 


\section{OVARIAN METASTASES OF BREAST CARCINOMA}

Patients with mutations in the BRCA1 and BRCA2 genes have a high risk for developing breast malignancies but also ovarian neoplasia. (21) Breast cancer metastatic to the ovary may be of ductal (most commonly metastasize to the ovary) or lobular type (the most common type of breast carcinoma). Sometimes metastatic ovarian tumor is identified before the detection of the primary tumor and sometimes microscopic ovarian metastases are present in patients with breast carcinoma undergoing prophylactic oophorectomy.

Ovarian metastases from breast neoplasia, are frequently bilateral. $(22,23)$ Grossly, the ovaries are enlarged, with a smooth surface but with a nodular appearance. Histologically, ovarian metastatic ductal carcinoma can simulate a primary ovarian endometrioid adenocarcinoma. A study of 64 patients with ovarian metastases originating from breast adenocarcinomas showed a median time of survival of 16 months after the diagnosis of ovarian metastases. (22)

\section{OVARIAN METASTASES FROM CERVICAL CANCER}

Ovarian metastases originating from squamous cell carcinoma of the cervix are rare and occur in

\section{REFERENCES}

1. Kuwabara Y., Yamada T., Yamazaki K., Du W.L., Banno K., Aoki D. et al. Establishment of an ovarian metastasis model andpossible involvement of E-cadherin down-regulationin the metastasis doi: 10.1111/j.1349-7006.2008.00946.x Cancer Sci, October 2008, vol. 99, no. 10.

2. McCluggage W.G., Wilkinson N. Metastatic neoplasms involving the ovary: a review withan emphasis on morphological and immunohistochemical features Histopathology 2005; 47, 231-247. DOI: 10.1111/j.1365-2559.2005.02194.x

3. Bullon A., Arseneau J., Prat J., Young R.H., Scully R.E. Tubular Krukenberg tumor. A problem in histopathologic diagnosis. Am J Surg Pathol. 1981; 5: 225-232.

4. Moghazy D., Al-Hendy O., Al-Hendy A. Krukenberg tumor presenting as back pain and apositive urine pregnancy test: a case report and literature review. Journal of Ovarian Research 2014; 7:36.

5. Young R. From Krukenberg to today: the ever present problems posedby metastatic tumors in the ovary: part I. Historical perspective, generalprinciples, mucinous tumors including the krukenberg tumor. Adv Anat Pathol. 2006; 13:205-227.

6. Hornung M., Vogel P., Schubert T., Hans-Jürgen Schlitt, Ulrich Bolder. A case of virilization induced by a Krukenberg tumor from gastric Cancer. World Journal of Surgical Oncology 2008; 6:19 doi:10.1186/1477-7819-6-19. less than $1 \%$ of cases. In his study, Nakanishi et al discovered an incidence of ovarian metastases of $1.3 \%$ for squamous cell carcinoma of the cervix and $6.3 \%$ in the case of cervical adenocarcinoma. In the majority of cases with metastatic ovarian tumors the neoplasic disease was very advanced, with the primary tumors extending to the body of the uterus. In a study by Tabata et al (24) ovarian metastases were found in 104 of 597 cases $(17.4 \%)$ of cervical squamous cell carcinoma. The majority of the ovarian metastases from cervical cancer are microscopic, unilateral, isolated from ovarian parenchyma and most frequently detected postoperatively.

Independent risk factors for the occurrence of ovarian metastases are age, tumor staging, histological type other than squamous, and the involvement of the uterine body. (25-29) The dissemination pathways of the cervical cancer to the ovaries include hematologic metastasis, lymphatic drainage and tubal drainage. Extensive invasion of the uterine body may potentiate these mechanisms.
7. McGill F.M., Ritter D.B., Rickard C.S., Kaleya R.N., Wadler S., Greston W.M., O'Hanlan K.A. Krukenberg tumors: can management beimproved? Gynecol Obstet Invest.1999; 48:61-65.

8. Kim H.K., Heo D.S., Bang Y.J., Kim N.K. Prognostic factors of Krukenberg's tumor. Gynecol Oncol. 2001; 82:105-109.

9. Cheong J.H., Hyung W.J., Chen J., Kim J., Choi S.H., Noh S.H. Surgical Management and Outcome of Metachronous Krukenberg Tumors From Gastric Cancer. Journal of Surgical Oncology. 2004; 87:39-45.

10. Lee K.R., Young R.H. The distinction between primary and metastatic mucinous carcinomas in the ovary. Gross and histologic findings in 50 cases. Am J Surg Pathol. 2003; 27:281-292.

11. Berezowski K., Stasny J.F., Kornstein M.J. Cytokeratins 7 and 20 and carcino embryonic antigen in ovarian and colonic carcinoma. Mod Pathol. 1996; 9: 1040-1044.

12. Park S.O., Kim H.S., Hong E.K., Kim A.W.H. Expression ofcytokeratins 7 and 20 in primary carcinomas of the stomach and colorectum and their value in the differential diagnosis of metastatic carcinomas to the ovary. Hum Pathol. 2002; 33:1078-1085.

13. Lagendijk J.H., Mullink H., van Diest P.J., Meijer G.A., Meijer C.J. Immunohistochemical differentiation between primary adenocarcinomas of the ovary and ovarian metastases of colon and 
breast origin. Comparison between a statistical and intuitive approach. J Clin Pathol. 1999; 52: 283-290.

14. Uewa G., Sawada M., Ogawa H. et al. Immunohistochemical study of cytokeratin 7 for the differential diagnosis of adenocarcinoma in the ovary. Gynecol Oncol. 1993; 51: 219-223.

15. Cuatrecasas M., Matias-Guiu X., Prat J. Synchronous mucinoustumors of the appendix and the ovary associated withpseudomyxoma peritonei. A clinicopathologic study of six cases with comparative analysis of c-Ki-ras mutations. Am J Surg Pathol. 1996; 20: 739-746.

16. Prayson R.A., Hart W.R., Petras R.E. Pseudomyxoma peritonei: a clinicopathologic study of 19 cases with emphasis on site oforigin and nature of associated ovarian tumors. Am J SurgPathol. 1994; 18 : 591-603.

17. Young R.H., Gilks C.B., Scully R.E. Mucinous tumors of theappendix associated with mucinous tumors of the ovary andpseudomyxoma peritonei: a clinicopathologic analysis of 22 cases supporting an origin in the appendix. Am J Surg Pathol.1991; 15: 415-429.

18. Kahn M.A., Demopoulos R.I. Mucinous ovarian tumors with pseudomyxoma peritonei: a clinicopathologic study. Int JGynecol Pathol. 1992; 11: 15-23.

19. Ronnett B.M., Kurman R.J., Zahn C.M. et. al. Pseudomyxoma peritonei in women: a clinicopathologic analysis of 30 caseswith emphasis on site of origin, prognosis and relationshipto ovarian mucinous tumors of low malignant potential. Hum Pathol. 1995; 56: 509-524.

20. Merino M.J., Edmonds P., LiVolsi V. Appendiceal carcinoma metastatic to the ovaries and mimicking primary ovariantumors. Int J Gynecol Pathol. 1985; 4: 110-120
21. Struewing J.P., Hartge P., Wacholder S. et. al. The risk of cancerassociated with specific mutations of BRCA1 and BRCA2among Ashkenazi Jews. N Engl J Med. 1997; 336: 1401-1408.

22. Gagnon Y., Tetu B. Ovarian metastases of breast carcinoma. A clinico-pathologic study of 59 cases. Cancer 1989; 64:892-898.

23. Young R.H., Carey R.W., Robboy S.J. Breast cancer masquerading as primary ovarian neoplasm. Cancer 1981; 48: 210-212.

24. Tabata M., Ichinoe K., Sakuragi N., Shiina Y., Yamaguchi T., Mabuchi Y. Incidence of ovarian metastasis in patients with cancer of the uterinecervix. Gynecol Oncol 1987, 28(3):255-261.

25. Nguyen L., Brewer C.A., DiSaia P.J. Ovarian metastasis of stage IB1squamous cell cancer of the cervix after radical parametrectomy andoophoropexy. Gynecol Oncol 1998, 68(2):198-200.

26. Rasmussen R.B., Rasmussen B.B., Knudsen J.B. Metastasis from squamouscarcinoma of the cervix stage $1 \mathrm{~B}$ to a borderline cystadenoma of theovary. Acta Obstet Gynecol Scand 1992, 71(1):69-71.

27. Morice P., Haie-Meder C., Pautier P., Lhomme C., Castaigne D. Ovarian metastasis on transposed ovary in patients treated for squamous cell carcinomaof the uterine cervix: report of two cases and surgical implications. Gynecol Oncol 2001, 83(3):605-607.

28. Atamdede F., Kennedy A.W. Adnexal recurrence of stage IB squamous cellcervical carcinoma after radical surgery and oophoropexy. A case report. J Reprod Med 1989, 34(3):244-246.

29. Cassidy L.J., Kennedy J.H. Ovarian metastasis from stage $1 B$ squamouscarcinoma of the cervix. Case report. Br J Obstet Gynaecol 1986, 93(11):1169-1170. 